\title{
Evaluation of Water Delivery Performance of Nkhafi Irrigation Scheme in Dowa District, Malawi, Africa
}

\author{
Davis Sibale ${ }^{1 *}$, Godfrey Mwenelupembe², Sylvester Chikabvumbwa², Sylvester Chisale ${ }^{3}$ \\ ${ }^{1}$ Department of Land and Water Resources, Lilongwe University of Agriculture and Natural Resources, Lilongwe, Malawi \\ ${ }^{2}$ Department of Civil Engineering (Water), University of Malawi, The Polytechnic, Blantyre, Malawi \\ ${ }^{3}$ Department of Applied Studies, Malawi University of Science and Technology, Thyolo, Malawi \\ Email: *dsibale222@gmail.com
}

How to cite this paper: Sibale, D., Mwenelupembe, G., Chikabvumbwa, S. and Chisale, S. (2021) Evaluation of Water Delivery Performance of Nkhafi Irrigation Scheme in Dowa District, Malawi, Africa. Computational Water, Energy, and Environmental Engineering, 10, 95-107.

https://doi.org/10.4236/cweee.2021.103007

Received: April 13, 2021

Accepted: May 31, 2021

Published: June 3, 2021

Copyright $\odot 2021$ by author(s) and Scientific Research Publishing Inc. This work is licensed under the Creative Commons Attribution International License (CC BY 4.0).

http://creativecommons.org/licenses/by/4.0/

\begin{abstract}
This study evaluated the water delivery performance of Nkhafi irrigation scheme based on adequacy, water delivery efficiency, equity, dependability and irrigation efficiency. Primary data were collected from field measurements, scheduled interviews, group discussions and use of a structured questionnaire. CROPWAT 8.0 computer model was used to determine crop water requirements and irrigation requirements. The results revealed that adequacy, water delivery efficiency, equity, dependability and overall water delivery performance were $(0.74 ; 0.82),(0.70 ; 0.80),(0.15 ; 0.20),(0.11 ; 0.21)$ and $(0.80$; $0.80)$ for 2017 and 2018 seasons respectively. The scheme overall irrigation efficiencies were $20 \%$ and $25 \%$ for 2017 and 2018 respectively. These findings revealed that scheme users failed to deliver adequate and dependable water in an effective manner in both growing seasons. This occurred due to insufficient water supply, poor irrigation scheduling, lack of adequate knowledge and skills in operating and rehabilitating hydraulic structures, siltation and water losses through seepage in canals. Therefore, it is recommended that major maintenance works need to be done along the whole canal network in order to achieve good overall water delivery performance. Furthermore, farmers need to be trained in water management, sustainable agricultural production practices, operation and maintenance of irrigation structures. The study has provided an insight on the status of the scheme hence encouraging scheme users to improve water delivery performance.
\end{abstract}

\section{Keywords}

Adequacy, Water Delivery Efficiency, Equity, Dependability, Irrigation Efficiency 


\section{Introduction}

In Malawi, dwindling of water resources due to climate change impacts has resulted into increasing water scarcity in most areas. Rainy seasons have become unpredictable and droughts have been more frequent in the last decades due to climate change and variability [1]. Water users in agriculture sector are facing challenges to access adequate water due to increasing drought frequency and erratic rainfall. The changing climate with greater rainfall uncertainty has created severe problems in managing and supplying freshwater supplies [2]. Climate change has also increased hydrological variability in most areas, making it more difficult to satisfy the increasing water demands. It poses a threat to sustainability of water resources [3] [4]. More emphasis has now been drawn into efficient use of irrigation water in order to maximise economic return and water resources sustainability. This calls for effective ways of managing water resources in irrigated agriculture in Malawi.

Erratic rains due to climate change have affected effective production of food crops. Irrigation development is a viable option for increasing agricultural production in the country. Irrigated agriculture is a major water user; however, there is low performance in water delivery in most irrigation schemes. Water management activities are performed by farmers themselves; furthermore, they also lack technical capacity to manage water properly. Other factors contributing to low performance of many irrigation schemes include: poor system's design and construction, poor water management approaches, poor operation and maintenance of irrigation infrastructure. These drawbacks further contribute to poor water delivery performance in irrigation schemes [5].

In irrigated agriculture, transferring water with minimum losses can help to increase irrigation efficiency, hence saving large quantities of water resources. The conveyance, distribution and application systems need to be in good condition in order to minimise water losses. One of the possible approaches is to improve water delivery performance of existing irrigation schemes. In most Malawian smallholder irrigation schemes, much attention focuses on production and outputs from the scheme and little attention is given to the water delivery performance in the schemes. As a case study, Nkhafi irrigation scheme was chosen for an evaluation of water delivery performance. The study was conducted to analyze the performance of the surface irrigation system in relation to water delivery performance indicators which included: adequacy, water delivery efficiency, dependability, equity and irrigation efficiency. Fan et al. [6] reported that assessing the performance of an irrigation system is an imperative step in enhancing sustainable agriculture water management. The findings from the study would help to point out where problems exist in the system and provide proper guidance to scheme managers and users on effective operation, maintenance and management of the scheme. 


\section{Previous Studies}

Gomo et al. [7] conducted a research study on technical performance of the Mooi River irrigation scheme. It was discovered that poor water management practices contributed to a situation of having shortage of water in the scheme. Farmers knew the causes of the water shortage but needed external support in order to ensure water is equitably distributed. Vandersypen et al. [8] evaluated the irrigation performance of the Office du Niger (Mali) in 1995 and 2004 using equity, dependability, adequacy and efficiency. They found that irrigation delivery service was excellent due to timely physical rehabilitation of the irrigation network. Mohammadi et al. [9] conducted an assessment of Varamin irrigation scheme in Iran. The results of their research showed that most of the structures were poorly being operated, leading to unfair delivery and wastage of much water during water distribution. Ortiz [10] conducted a research study in Tumbaco irrigation system, located in the province of Pichincha, Republic of Ecuador, to determine conveyance, distribution, application and overall irrigation efficiencies. The results showed that the conveyance, distribution, application and overall irrigation efficiencies were $78.82 \%$ (regular), 37.95\% (poor), 60.72\% (good) and $18.17 \%$ (poor) respectively. The poor overall irrigation efficiency was affected by the disparity in water distribution to the users. The timing of water delivery assigned by water user association did not take into account the real discharge delivered to the users neither to the crop water requirements, creating inequity, conflicts between users as well as over and under irrigation.

\section{Materials and Methods}

\subsection{Study Area}

The study was conducted at Nkhafi irrigation scheme (Longitude: $33.6^{\circ}$, Latitude: $13.4^{\circ}, 1115 \mathrm{~m}$ above sea level), about $68 \mathrm{~km}$ north of Lilongwe, the capital city of Malawi. The mean rainfall per year in the study area is $62.5 \mathrm{~mm}$ with the maximum of $104.5 \mathrm{~mm}$ and minimum of $20.4 \mathrm{~mm}$. The average temperatures range from $19.4^{\circ} \mathrm{C}$ and $21.3^{\circ} \mathrm{C}$. Figure 1 shows location of the irrigation scheme.

\subsection{Data Collection}

Primary data were collected from field measurements carried out within the scheme. Such measurements included: flow velocity, canal dimensions, and actual water surface elevation in canals and volume of water supplied to each block of the scheme. Measurement of canal water flow was done by applying the velocity-area method. CROPWAT 8.0 Computer model was used to determine crop water requirements and irrigation requirements (IR). The input data for CROPWAT model included; climatic data of the study area, soil texture, type of crops, crop coefficient, root depth, depletion factor, available soil moisture, basic infiltration rate, and irrigation efficiency. Daily and monthly reference Crop Evapo-transpiration (ETO) was estimated based on FAO Penman-Monteith method. The volume of water required to feed the main and branch canals were 


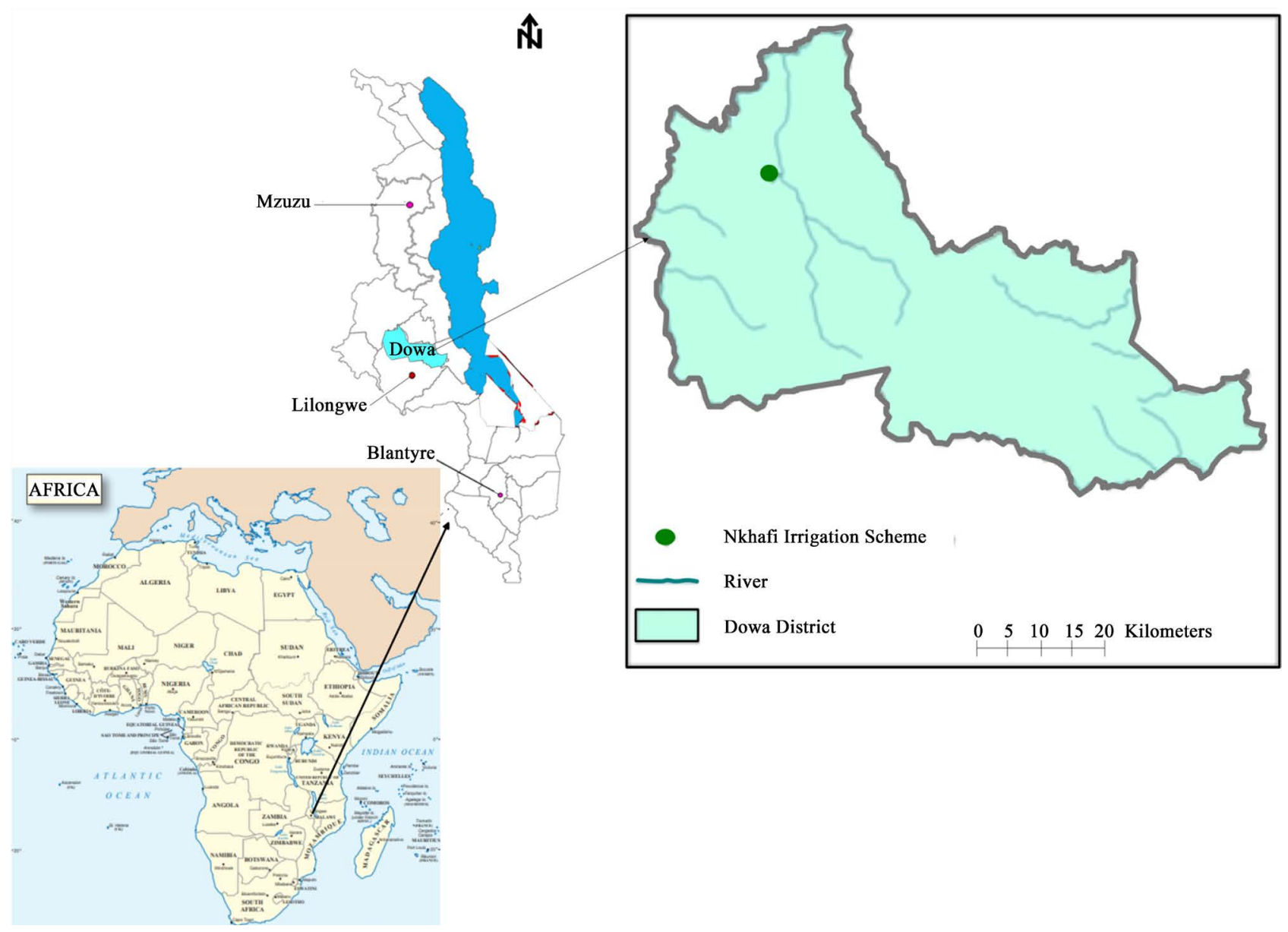

Figure 1. Location of Nkhafi Irrigation scheme.

estimated based on gross irrigation requirement and the command area served.

Data collection was carried out in collaboration with scheme users (farmers), WUA executive members, Agricultural extension development officers, irrigation officers and chiefs. To get information from targeted respondents, a structured questionnaire containing both open and closed-ended questions was used. This approach was incorporated in the study in order to assess the perceptions of water users regarding the irrigation service delivery and identify factors that affect water delivery at the study area. Data on climate, crops under irrigation, actual command areas, canal discharge, and features of hydraulic structures, were fully utilized in the study.

\subsection{Water Delivery Performance Indicators}

Adequacy, water delivery efficiency, equity, dependability and irrigation efficiency were the key internal water delivery performance indicators in this study.

\subsubsection{Adequacy}

According to Molden and Gates [11], adequacy is a measure that reveals if the required amount of water is adequately supplied to crops under irrigation. It is a measure of the ability of an irrigation system to meet targeted deliveries in terms 
of quantity [12]. Adequacy was determined using Equation (1):

$$
\begin{gathered}
P_{A}=\frac{1}{T} \sum \frac{1}{R}\left(\sum p A\right) \\
\text { and } p A=\frac{Q_{D}}{Q_{R}}
\end{gathered}
$$

where, $P_{A}$ is performance measure relative to adequacy at subsystem or system level, $p A$ is adequacy for a single point (delivery performance ratio), $Q_{D}$ is the actual amount of water delivered per block, $Q_{R}$ is the required amount of water, $R$ is the region served by the system and $T$ is the irrigation time.

\subsubsection{Water Delivery Efficiency}

This clearly shows the amount of water wasted by checking the amount of water delivered and the amount of water required per block. The water delivery efficiency was determined using Equation (2):

$$
\begin{gathered}
P_{F}=\frac{1}{T} \sum \frac{1}{R}(p F) \\
\text { and } p F=\frac{Q_{R}}{Q_{D}}
\end{gathered}
$$

where, $P_{F}$ is the performance measure of water delivery efficiency, $p F$ is the adequacy for a single point (delivery performance ratio), $Q_{D}$ is the actual amount of water delivered per block, $Q_{R}$ is the required amount of water, and $R$ is the region served by the system, and $T$ is the time period.

\subsubsection{Equity}

Equity is a measure of water delivery fairness among water users and is given by a coefficient $C V_{R}$ which measures spatial variation of the ratio of the amount of water delivered to the required amount of water. Equity was determined using Equation (3):

$$
P_{E}=\frac{1}{T} \sum C V_{R}\left(\frac{Q_{D}}{Q_{R}}\right)
$$

where, $P_{E}$ is the performance measure relative to equity, $C V_{R}\left(\frac{Q_{D}}{Q_{R}}\right)$ is the spatial coefficient of variation of the ratio $\left(Q_{D} / Q_{R}\right)$ over the region $(R), R$ is the region served by the system, and $T$ is the irrigation time.

\subsubsection{Dependability or Reliability}

This is an important indicator because it shows the reliability of the system to meet the expected water deliveries. Dependability was determined using Equation (4):

$$
P_{D}=\frac{1}{R} \sum C V_{T}\left(\frac{Q_{D}}{Q_{R}}\right)
$$

where, $P_{D}$ is the performance measure relative to dependability or reliability, 
$C V_{T}\left(\frac{Q_{D}}{Q_{R}}\right)$ is the temporal coefficient of variation, $R$ is the region served by the system, and $T$ is the irrigation time.

\subsubsection{Overall Performance Indicator (OPI)}

The overall performance indicator varies from 0 to 1 . After determining the adequacy, water delivery efficiency, equity and dependability, the OPI was measured and evaluated using Equation (5) below:

$$
\mathrm{OPI}=\frac{P_{A}+P_{F}+\left(1-P_{E}\right)+\left(1-P_{D}\right)}{4}
$$

where, OPI is the overall performance indicator, $P_{A}$ is the performance measure relative to adequacy, $P_{F}$ is the performance measure of water delivery efficiency, $P_{E}$ is the performance measure relative to equity, and $P_{D}$ is the performance measure relative to dependability or reliability.

For effective decision making, the water delivery indicators were compared with acceptable standard indicators presented in Table 1.

Table 1. Standard water delivery indicators (Molden and Gates, [11]).

\begin{tabular}{cccc}
\hline \multirow{2}{*}{ Water delivery indicator } & \multicolumn{3}{c}{ Performance class } \\
\cline { 2 - 4 } Adequacy $\left(P_{A}\right)$ & Good & Fair & Poor \\
Water delivery efficiency $\left(P_{F}\right)$ & $0.90-1.00$ & $0.80-0.89$ & $<0.80$ \\
Equity $\left(P_{E}\right)$ & $0.85-1.00$ & $0.70-0.84$ & $<0.70$ \\
Dependability $\left(P_{D}\right)$ & $0.00-0.10$ & $0.11-0.25$ & $>0.25$ \\
Overall performance indicator $(\mathrm{OPI})$ & $0.00-0.10$ & $0.11-0.20$ & $>0.20$ \\
\hline
\end{tabular}

\subsubsection{Irrigation Efficiency}

Performance assessment using irrigation efficiencies both involved infield application efficiencies and overall scheme efficiency. To determine these efficiencies, flow measurement was carried out on strategic points along conveyance, distribution and application systems. The canals were divided into sections such that each section covered a particular block. The water velocity was measured on various sections of the canals. Canal design parameters were checked and verified with existing parameters which included: flow depth, top water width, canal top width, bed width, side slope, bed slope and wetted perimeter.

After knowing the flow rate at the inlet and outlet of each conveyance and distribution system, the conveyance and distribution efficiencies were determined. As for application efficiency, the amount of water supplied to a particular field was measured and soil water content on representative points throughout the field was determined before and after the irrigation. After gathering the much-needed data, the following formulae were used to calculate the required irrigation efficiencies: 
1) Conveyance Efficiency

$$
E_{c}=\frac{W_{o}}{W_{s}} \times 100
$$

where, $E_{c}$ is water conveyance efficiency, $W_{o}$ is the volume of water released from the conveyance system, and $W_{s}$ is the volume of water delivered into the system from the source.

\section{2) Distribution Efficiency}

$$
E_{d}=\frac{W_{f}}{W_{b}} \times 100
$$

where, $E_{d}$ is distribution efficiency, $W_{f}$ is the volume of water applied to the actual field, and $W_{b}$ is the volume of water supplied to the block of the field.

3) Application Efficiency

$$
E_{a}=\frac{W_{c}}{W_{f}} \times 100
$$

where, $E_{a}$ is the application efficiency, $W_{c}$ is the amount of water available for use by the crop in the root zone, and $W_{f}$ is the volume of water applied to the actual field.

4) Overall Irrigation Efficiency

$$
E_{p}=\frac{W_{c}}{W_{s}} \times 100
$$

where, $E_{p}$ is overall irrigation efficiency, $W_{c}$ is the amount of water available for use by the crop, and $W_{s}$ is the volume of water delivered into the system from the source.

Conveyance, distribution and water application efficiencies were checked as guided by Reddi and Reddy [13].

\section{Results and Discussion}

\section{Water Delivery Performance Indicators}

The results for adequacy, water delivery efficiency, equity, dependability and overall water delivery performance are presented in Table 2.

According to the results in Table 2, the overall adequacy was "poor" in 2017

Table 2. Water delivery performance indicators.

\begin{tabular}{cccccc}
\hline \multirow{2}{*}{ Water delivery performance indicators } & \multicolumn{2}{c}{2017} & \multicolumn{2}{c}{2018} \\
\cline { 2 - 5 } & Value & Decision & Value & Decision \\
\hline Adequacy $\left(P_{A}\right)$ & 0.74 & poor & 0.82 & Fair \\
Water delivery efficiency $\left(P_{F}\right)$ & 0.70 & Fair & 0.80 & Fair \\
Equity $\left(P_{E}\right)$ & 0.15 & Fair & 0.20 & Fair \\
Dependability $\left(P_{D}\right)$ & 0.11 & Fair & 0.21 & Poor \\
Overall water delivery performance (OPI) & 0.80 & Fair & 0.80 & Fair \\
\hline
\end{tabular}


season and "fair" in 2018 season. The findings revealed a gradual trend in terms of supplying the required volume of water in irrigation blocks. In both seasons, it showed that water delivery did not meet crop water requirement. Water supply was not adequate to satisfy water demand due to the decline of water levels from the source and excessive water losses in the conveyance and distribution systems. Lack of capacity to repair water supply systems contributed to an increase in water losses along the supply systems.

In the same process of water delivery in the irrigation scheme, the overall water delivery efficiency was "fair" for both 2017 and 2018 growing seasons. Though there was fair water delivery efficiency, siltation and water losses during delivery process were in existence at the irrigation scheme. This was attributed to poor water management, poor operation and maintenance of the system. It was further noted that there was malfunctioning of flow control structures and poor monitoring of water distribution systems.

Overall equity was "fair" for both 2017 and 2018 growing seasons. The findings revealed that water delivery was not uniform as expected in the system. Overtime, it was discovered that there was a great disparity in water distribution on each outlet. The results reveal that additional efforts are required to improve water delivery and distribution in the fields with respect to time, quantity and crop water demand. Proper irrigation scheduling and restoration of flow control structures can help to improve the overall equity in the scheme.

Further confirmation was observed on system's dependability where the overall dependability was "fair" in 2017 season and "poor" in 2018. The findings revealed that water was distributed fairly on time in 2017 season and distributed poorly in 2018 season. Some gated structures were in poor condition hence failed to function properly. There was uncontrolled flow of water. This contributed to attainment of poor trend of dependability or reliability $\left(P_{D}\right)$.

Upon considering adequacy, water delivery efficiency, equity, and dependability, the overall water delivery performance (OPI) was fair for both seasons (2017 and 2018). Even though the overall water delivery was fair, the required water was not delivered to field blocks as expected. This occurred due to lack of water measuring devices, insufficient water supply, and lack of competency in operating hydraulic structures. The wasted water through seepage in canals also affected the overall water delivery performance. Therefore, major maintenance works need to be done along the whole canal network in order to achieve good overall water delivery performance. The results align with the findings of Agide et al. [14] which emphasized on the need of scheme rehabilitation in order to improve water supply, distribution and application.

In assessing the performance of Nkhafi irrigation scheme in terms of water delivery, the results on conveyance, distribution, application and overall irrigation efficiencies were also helpful. The results are presented in Figure 2.

According to [15], the attainable application efficiency ranges from 55\% $70 \%$. Based on the results, the application efficiency was below the required 


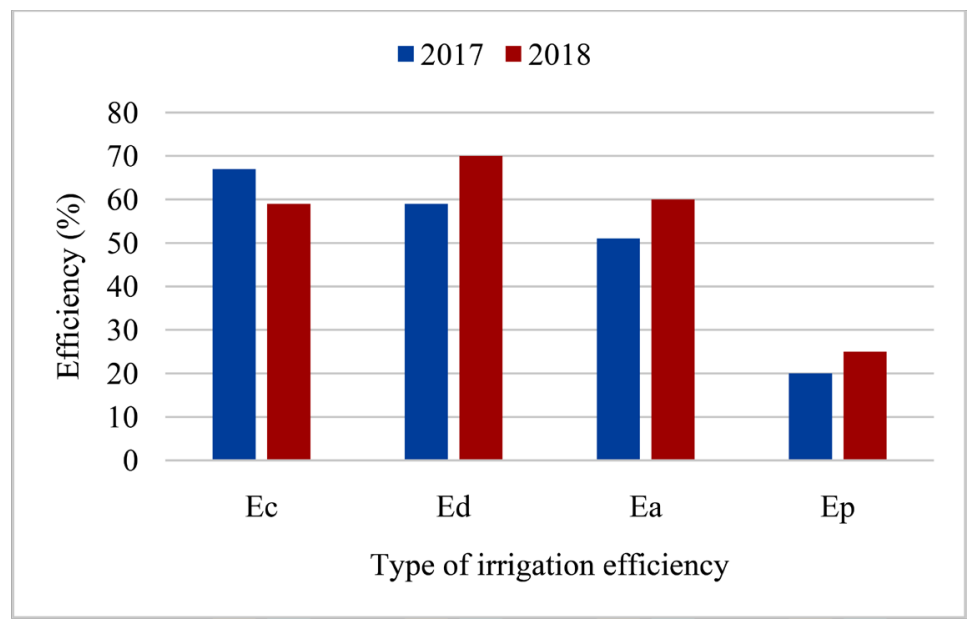

$E_{c}$ is the Conveyance efficiency, $E_{d}$ is the distribution efficiency, $E_{a}$ is the application efficiency and $E_{p}$ is the overall irrigation efficiency.

Figure 2. Irrigation efficiencies at the scheme.

range in 2017 season and improved to $60 \%$ in 2018 season. According to the study conducted by [16], the distribution efficiency should be $\geq 60 \%$. The results from this study revealed that the distribution efficiency was below $60 \%$ in 2017 season and improved to $70 \%$ in 2018 season. According to [17], the acceptable conveyance efficiency is $90 \%$ and $70 \%$ for lined and unlined canals respectively. In reference to Figure 2, the conveyance efficiencies at the scheme were below the acceptable limit in both seasons. This clearly shows that there is laxity in managing water in the conveyance system.

In a surface irrigation scheme, overall irrigation efficiency of $50 \%-60 \%$ is considered to be good; $40 \%$ is considered to be reasonable, while overall irrigation efficiency of less $40 \%$ is poor [18]. Though there was an improvement in distribution and application efficiency from 2017 season to 2018 season, the overall irrigation efficiency was poor in both seasons. In reference to Figure 2, the results show that the scheme overall irrigation efficiency was $20 \%$ and $25 \%$ for 2017 and 2018 growing seasons respectively. This revealed that more water was wasted in the scheme due to poor water management practices. It was also noted that water was being delivered to field blocks without knowing the quantity of water to apply and the exact time of water application. Therefore, to improve water management, irrigation scheduling would help in matching the right quantity of water to apply based crop water requirement. Proper field leveling is also required at the scheme. Desilting and effective lining need to be intensified in the distribution network in order to minimize the seepage losses. Trainings in water management should also be targeted to all farmers participating in scheme activities. The study has also revealed the need for high level technical knowledge as indicated in Table 3. Absence of supportive training on best irrigation practices to guide sustainable water management and irrigation scheduling further result into low performance of water delivery in an irrigation scheme. 
In reference to Table 3, majority of the farmers revealed that there are no local technical experts to offer support services to the irrigation scheme. Unavailability of qualified local technical experts to repair irrigation structures implies that there is a technical gap which influences negatively to sustainability of the scheme.

From Table 4, it is evident that majority of the farmers revealed that there are no trained committees to handle water management systems. Lack of skills to handle water management systems also led to inefficiency in managing water distribution and application. This study noted that limited abilities, skills and knowledge of farmers in operation and maintenance of the scheme affected the efficiencies at the scheme. These results concur with the findings of Dejen et al. [19] and Ulsido [20] who found out that limited trainings on irrigation water management leads to low performance of an irrigation scheme. Yami and Snyder [21] extended that farmers' trainings in irrigation water management are crucial in ensuring sustainable irrigation development.

Performance and sustainability of the scheme also relies on availability of materials for maintenance work. It is evident from Table 5 that majority of the farmers agreed that materials for maintenance are available within the study area. The availability of materials for maintenance work is an indication that water system's structures can be fixed whenever a breakdown occur without delays. This greatly influences sustainability positively.

Table 3. Availability of local technical experts to provide support services.

\begin{tabular}{ccc}
\hline Local technical experts & Frequency (F) & Percentage (\%) \\
\hline Yes & 7 & 14 \\
No & 43 & 86 \\
Total & 50 & 100 \\
\hline
\end{tabular}

Table 4. Availability of trained committees to handle water management systems.

\begin{tabular}{ccc}
\hline Trained committees & Frequency (F) & Percentage (\%) \\
\hline Yes & 5 & 10 \\
No & 45 & 90 \\
Total & 50 & 10 \\
\hline
\end{tabular}

Table 5. Availability of materials for maintenance work.

\begin{tabular}{ccc}
\hline Materials for maintenance work & Frequency (F) & Percentage (\%) \\
\hline Yes & 35 & 70 \\
No & 15 & 30 \\
Total & 50 & 100 \\
\hline
\end{tabular}

\section{Conclusion}

An evaluation of water delivery performance of Nkhafi irrigation scheme was a 
practical exercise that provided a better understanding on how water is conveyed, distributed and applied in the scheme. The water delivery performance of Nkhafi irrigation scheme was evaluated using adequacy, water delivery efficiency, equity, dependability and irrigation efficiency. The results revealed that there was fair overall water delivery performance at the scheme. Furthermore, the study revealed that the overall irrigation efficiency was poor. This confirms that there was a disparity in water distribution at the scheme. Though the overall water delivery performance of Nkhafi irrigation scheme was classified as "fair", much work needs to be done in order to improve its performance. The system can become more dependable by carrying out major maintenance works along the whole canal network and implementing effective irrigation scheduling. With the current impact of climate change on water resources, farmers at the scheme need to be trained in water management, sustainable agricultural production practices, operation and maintenance of irrigation structures. The study has provided an insight on the status of the scheme hence encouraging scheme users and other stakeholders involved to improve water delivery performance.

\section{Acknowledgements}

Authors would like to extend great thanks to Nkhafi irrigation scheme users, WUA executive members, agricultural extension development officers, irrigation officers and chiefs for spending their time to provide required information that was very helpful in the study.

\section{Conflicts of Interest}

The authors declare no conflicts of interest regarding the publication of this paper.

\section{References}

[1] AGRA (Alliance for a Green Revolution in Africa) (2014) Africa Agriculture Status Report: Climate Change and Smallholder Agriculture in Sub-Saharan Africa. Alliance for a Green Revolution in Africa, Nairobi.

[2] Falloon, P. and Betts, R. (2010) Climate Impacts on European Agriculture and Water Management in the Context of Adaptation and Mitigation-The Importance of an Integrated Approach. Science of the Total Environment, 408, 5667-5687. https://doi.org/10.1016/j.scitotenv.2009.05.002

[3] Oti, J.O., Kabo-bah, A.T. and Ofosu, E. (2020) Hydrologic Response to Climate Change in the Densu River Basin in Ghana. Heliyon, 6, e04722. https://doi.org/10.1016/j.heliyon.2020.e04722

[4] Pham, B.Q., Yu, P.S., Yang, T.C., Kuo, C.M. and Tseng, H.W. (2017) Assessment of Climate Change Impacts on Hydrological Processes and Water Resources by Water Evaluation and Planning (WEAP) Model: Case Study in THAC MO Catchment, Vietnam. Proceedings of the 37th IAHR World Congress, Kuala Lumpur, 13-18 August 2017, 4312-4321.

[5] Gotosa, J., Gichuki, F.N. and Senzanje, A. (2002) Performance Assessment of Water Delivery to a Smallholder Irrigation Scheme in Zimbabwe, Nyanyadzi Case Study. Journal of Applied Science in Southern Africa, The Journal of the University of Zim- 
babwe, 8, 37-52.

[6] Fan, Y., Gao, Z., Wang, S., Chen, H. and Liu, J. (2018) Evaluation of the Water Allocation and Delivery Performance of Jiamakou Irrigation Scheme, Shanxi, China. Water, 10, Article No. 654. https://doi.org/10.3390/w10050654

[7] Gomo, T., Senzanje, A., Mudhara, M. and Dhavu, K. (2014) Assessing the Performance of Smallholder Irrigation and Deriving Best Management Practices in South Africa. Irrigation and Drainage, 63, 419-429. https://doi.org/10.1002/ird.1815

[8] Vandersypen, K., Bengaly, K., Keita, A.C., Sidibe, S., Raes, D. and Jamin, J.Y. (2006) Irrigation Performance at Tertiary Level in the Rice Schemes of the Office du Niger(Mali): Adequate Water Delivery through Over-Supply. Agricultural Water Management, 83, 143-152. https://doi.org/10.1016/j.agwat.2005.11.003

[9] Mohammadi, A., Parvaresh-Rizi, A. and Abbasi, N. (2018) Prospective of Water Distribution Based on the Performance of Hydraulic Structures in Varamin Irrigation scheme (Iran). Irrigation and Drainage, 68, 245-255.

https://doi.org/10.1002/ird.2301

[10] Ortiz, R. (2020) Conveyance, Distribution, Application, System and Global Efficiencies in the Tumbaco Irrigation System-Ecuador. Central University of Ecuador, Faculty of Agricultural Sciences, Jerónimo Leiton y Av. La Gasca s/n. Ciudadela Universitaria, Article No. 17052.

[11] Molden, D.J. and Gates, T.K. (1990) Performance Measures for Evaluation of Irrigation Water Delivery Systems. Journal of Irrigation and Drainage Engineering, 116, 804-823. https://doi.org/10.1061/(ASCE)0733-9437(1990)116:6(804)

[12] Renault, D. and Wahaj, R. (2005) Performance Indicators of Irrigation Service. Food and Agriculture Organisation (FAO), Water Development and Management Unit, Rome, 1-16.

[13] Reddi, S. and Reddy, Y. (2003) Efficient Use of Irrigation Water. Kalyani Publishing House, New Delhi.

[14] Agide, Z., Haileselassie, A., Sally, H., Erkossa, T. and Schmitter, P.S. (2016) Analysis of Water Delivery Performance of Smallholder Irrigation Schemes in Ethiopia, Diversity and Lessons across Schemes, Typologies and Reaches. Food and Agriculture Organization, Rome.

[15] Food and Agriculture Organization (FAO) (1989) Irrigation Manual: Planning, Development, Monitoring and Evaluation of Irrigated Agriculture with Farmers Participation. Vol. 2, Food and Agriculture Organization, Rome.

[16] Eisenhauer, D.E. (1997) Irrigation Performance Measures: Efficiency and Uniformity. Journal of Irrigation and Drainage Engineering, 123, 423-442. https://doi.org/10.1061/(ASCE)0733-9437(1997)123:6(423)

[17] Halcrow, W., et al. (1992) Infrastructure Operation and Maintenance Manual: Kapunga Project. National Agricultural and Food Cooperation, Tanzania.

[18] Machibya, M., Lankford, B. and Mdemu, M. (2004) Irrigation Efficiency and Productivity Manual, Tools for Irrigation Professionals and Practioners. Irrigation Efficiency and Productivity Workshop, Mbeya, May 2004.

https://www.academia.edu/29610159/Irrigation Efficiency and Productivity Man ual Tools for Irrigation Professionals and Practitioners

[19] Dejen, Z.A., Schultz, B. and Hayde, L. (2012) Comparative Irrigation Performance Assessment in Community-Managed Schemes in Ethiopia. African Journal of Agricultural Research, 7, 4956-4970. https://doi.org/10.5897/AJAR11.2135

[20] Ulsido, D.M. and Alemu, E. (2014) Irrigation Water Management in Small Scale Ir- 
rigation Schemes: The Case of the Ethiopian Rift Valley Lake Basin. Environmental Research, Engineering and Management, 67, 5-15.

https://doi.org/10.5755/j01.erem.67.1.6240

[21] Yami, M. and Snyder, K. (2012) Improving Sustainability of Impacts of Agricultural Water Management Interventions in Challenging Contexts, Case Study from Ethiopia. International Water Management Institute, Addis Ababa. 